\title{
Improvement of Wafer Saw Film Burr Issues
}

\author{
Te-Jen Su, Chien-Liang Chiu, Yi-Feng Chen, Shih-Mine Wang, Tung-Yen Tsou
}

\begin{abstract}
FOW (Film On Wire) is one method of stack die for IC assembly process. This film material would cover the gold wire which electrical conduction, to prevent the gold wire damage cause the product fail in the stack die chip on die bond process, but this film is easy to occur film burr issue during wafer dicing saw process. If film burr occur, it will cause die bond pad contamination, such that will cause gold wire can't eutectic with bond pad, and IC product will be fail then cause yield loss.
\end{abstract}

In this paper, experiment how to apply the blade dressing method improvement film burr issue, is also investigated developed new dressing board material to increase quality and reduce cost, thus achieving a win-win outcome.

Index Terms - FOW (Film On Wire), film burr, blade dressing

\section{INTRODUCTION}

During Mobile RAM IC package assembly process, occur a major abnormal, on wire bond process stage found the wafer bonding pad contamination issue, which would cause the gold wire can't eutectic with bonding pad, then cause product fail and yield loss. The contamination material come from Film Over Wire (FOW) film shown in Fig. 1, [1]-[3], this film were mounting on wafer backside before wafer dicing saw, then cutting with wafer dicing process, when the wafer dicing saw blade occur abnormal, it would cause wafer dicing blade ability reduce can't cutting the FOW film, then occur film burr issue shown in Fig. 2, this film burr would cause wafer bonding pad contamination. So, how to solve this abnormal issue was first priority project.

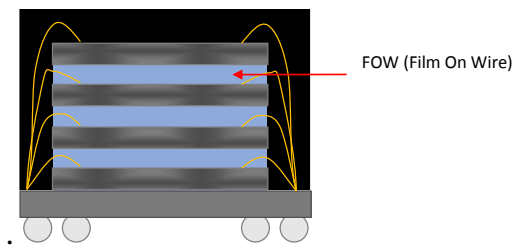

Fig. 1. FOW stack die type package.

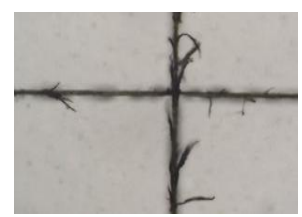

Fig. 2. FOW film burr on dicing tape.

Manuscript received September 14, 2015; revised October 30, 2015. The work was supported by the Ministry of Science and Technology ,R.O.C. of Taiwan under Grants MOST 103-2221-E-151-040

The authors are with National Kaohsiung University of Applied Sciences, Taiwan (e-mail: 2102305123@gm.kuas.edu.tw, sutj@cc.kuas.edu.tw, eagle@cc.kuas.edu.tw,wwang16@gmail.com).

\section{Root CAuse AnAlysis}

\section{A. Cause and Effect Analysis}

To investigate and analyze the film burr issue, the cause and effect (fishbone) diagram was applied. This method of analysis was based on major factors such as man, machine, material, and method to brainstorm all possible causes of the problem according to everyone's past experiences to detail various possible small factor cause analyses. The fishbone diagram of the FOW film burr issue is shown in Fig. 3.



Fig. 3. Film burr issue fish bone.

Based on the fishbone detail factor, we could one by one confirm, measure, and check the analysis. After the investigation found some abnormal phenomenon in material item wafer dicing blades, as presented in Table 1, the abnormal possible FOW film burr issue was found to be a major cause. Therefore, detailed study and experiments were necessary to find the root cause.

TABLE I: ABNORMAL FACTOR DETAILED ANALYSIS TABLE

\begin{tabular}{|c|c|c|c|}
\hline \multicolumn{2}{|c|}{ Check Item } & \multirow{2}{*}{$\begin{array}{l}\text { Check Result } \\
\text { Program correct }\end{array}$} & \multirow{2}{*}{$\begin{array}{l}\text { Judge } \\
\text { No Risk }\end{array}$} \\
\hline Man & Wrong program & & \\
\hline \multirow{2}{*}{ Machine } & Cutting water & Water flow is normal & No Risk \\
\hline & Blade height & $\begin{array}{l}\text { Blade height measure } \\
\text { is normal }\end{array}$ & No Risk \\
\hline \multirow{2}{*}{ Material } & Film abnormal & No abnormal & No Risk \\
\hline & $\begin{array}{l}\text { Dicing blade } \\
\text { abnormal }\end{array}$ & Found the abnormal & Risk \\
\hline \multirow{2}{*}{ Method } & $\begin{array}{l}\text { Film store over lift } \\
\text { time }\end{array}$ & No over lift time & No Risk \\
\hline & Cutting parameter & $\begin{array}{l}\text { Parameter within } \\
\text { SPEC. }\end{array}$ & No Risk \\
\hline
\end{tabular}

\section{B. Abnormal Wafer Dicing Blade Analysis}

According to the results of the characteristics of factor analysis, we found that the major possible root cause was from the wafer dicing blade. Therefore, the abnormal wafer 
dicing blade was analyzed by SEM. After observation, we found that the blade shape was uneven and damaged it's different with normal blade, and by a further detailed observation, we found that the blade surface was covered with some foreign glue-like material (Fig. 4), which may have reduced the blade's ability. The foreign material was analyzed by the EDX; we observed that the material consisted of the major elements $\mathrm{C}, \mathrm{Si}$, and $\mathrm{O}$. As this composition was the same as the FOW film glue element composition, we believe that the source of the foreign material came from the FOW film during the wafer dicing process.

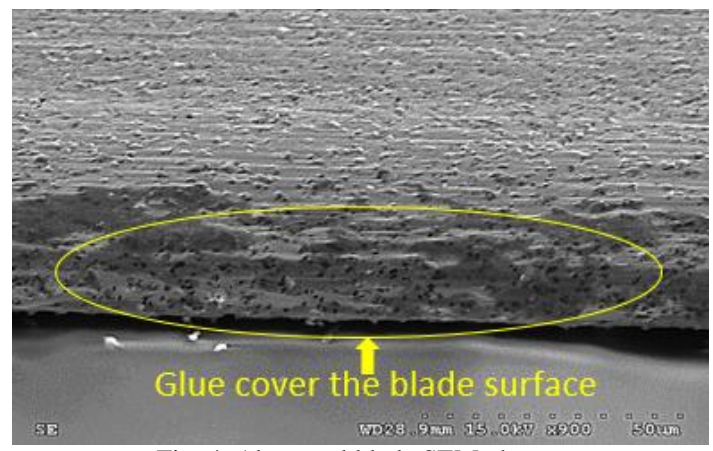

Fig. 4. Abnormal blade SEM photo.

\section{Wafer Dicing Blade Mechanical}

In the processing mechanism of the wafer dicing blade, the process of cutting and making a groove with the blade is called a "grinding" process, which shaves material from the wafer. This mechanism is similar to that of a saw cutting wood, where spaces between the grains of abrasive material such as the teeth of the saw play an important role.

Thus, if the blade surface grit covers the film glue, the blade cutting ability will decrease, which would then cause some abnormal like the film burr issue on wafer dicing process shown in Fig. 5.
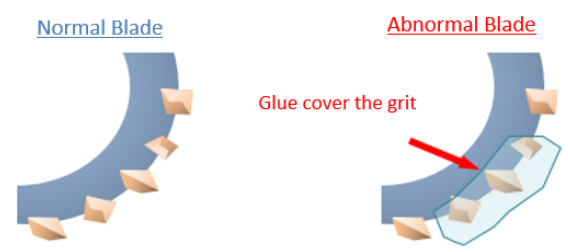

Fig. 5. Normal and abnormal blade compare.

\section{Simulation Experiment}

To confirm that the major cause abnormal dicing film burr issue and then we did a simulation experiment, take normal and abnormal wafer dicing blade then cutting the same film material and wafer, after experiment normal blade dicing chip not found the film burr issue, and abnormal blade which blade surface cover the film glue dicing chip found the film burr remain on the chip side, so it can prove the film burr issue were from the wafer dicing blade surface cover glue cause.

\section{EXPERIMENTAL METHOD}

\section{A. Dicing Blade Dressing Method}

According to the analysis results, the major cause of the issue was due to glue covering the wafer dicing blade, leading to a decrease in the cutting ability. Currently, there is a need to determine how to remove the blade surface glue. According to previous studies [4], [5], the application of the dressing board improves the topside chipping issue of the wafer dicing saw compared with the before method mirror wafer dressing mode.

Experiments using the dressing board for blade dressing, which covers the surface of the glue, found that this method can remove the blade surface glue, as shown in Fig. 6 .


Fig. 6. Blade before and after dressing SEM photo.

\section{B. Develop Dressing Board Material}

During the blade-dressing experiment, we found certain other problems. Because the wafer blade dicing saw is operated in the wet mode (a process that uses water to lower the temperature and clean silicon dust), we observed that water would cause dressing board warpage. If the warpage gap value was more than $1 \mathrm{~mm}$, this problem would cause damage or breakage of the wafer dicing blade because the blade exposure is only 670-710 um.

Thus, we studied to develop a new dressing board to solve the board warpage problem, as presented in Table II.

TABLE II: BLADE DRESSING BOARD MSDS

\begin{tabular}{|l|c|}
\hline Chemical Name & Content \\
\hline Aluminum Oxide & $80 \sim 90 \%$ \\
\hline Silicon Carbide & $10 \sim 15 \%$ \\
\hline Phenolic resins & $1 \sim 3 \%$ \\
\hline
\end{tabular}

After testing the new developed dressing board, we found that it could solve the warpage problem. Therefore, this new material was used to prepare three types of grit size boards to perform the next experiment, as shown in Table III and Fig. 7.

TABLE III: NEW DEVELOP DRESSING BOARD DATA SHEET

\begin{tabular}{|l|c|c|c|}
\hline Dressing Board Type & M3000 & M4000 & M5000 \\
\hline Grit Size & $1 \sim 3 \mathrm{um}$ & $2 \sim 6 \mathrm{um}$ & $4 \sim 8 \mathrm{um}$ \\
\hline
\end{tabular}

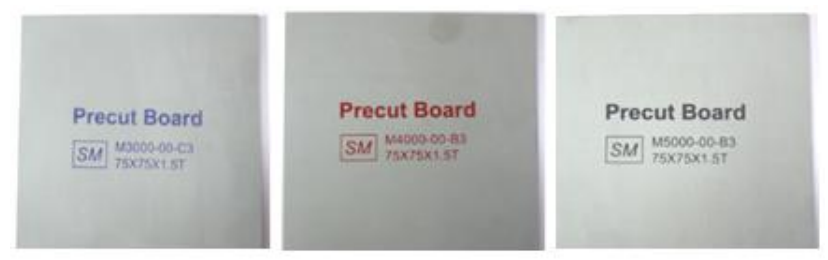

Fig. 7. New develop dressing board.

\section{Parameter Optimal Experiment}

From the previous experimental results, it was 
determined that the use of this method can solve problems that are currently being encountered, including film burr issues. However, based on the balance between considerations of mass production and factory production quality and costs, we must test a combination of optimized parameters and materials to satisfy the needs of the factory production line, machine UPH, and material costs. Therefore, the next step will be to optimize experimental parameters and conditions, include dressing length, board material, blade dressing rotation, blade depth, and blade speed (Table IV and Fig. 8).

\section{TABLE IV: DRESSING PARAMETER EXPERIMENT CONDITION}

\begin{tabular}{|l|c|c|c|}
\hline \multicolumn{1}{|c|}{ Factor } & Condition A & Condition B & Condition C \\
\hline 1. Dressing Length & $50 \mathrm{~m}$ & $100 \mathrm{~m}$ & $150 \mathrm{~m}$ \\
\hline 2. Board Material & $\# 3000$ & $\# 4000$ & $\# 5000$ \\
\hline 3. Blade Rotation & $40000 \mathrm{rpm}$ & $45000 \mathrm{rpm}$ & $50000 \mathrm{rpm}$ \\
\hline 4. Blade Depth & $100 \mathrm{um}$ & $150 \mathrm{um}$ & $200 \mathrm{um}$ \\
\hline 5. Blade Speed & Slow & Middle & High \\
\hline
\end{tabular}

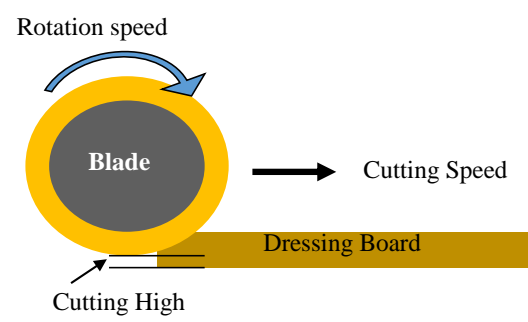

Fig. 8. Blade dressing parameter photo.

\section{EXPERIMENTAL RESULT}

\section{A. Optimal Dressing Board and Dressing Parameter}

After the experiments, we found the optimal blade dressing parameters and dressing board, where the dressing board with the optimum ratio was the M5000 type shown in Table 5, M4000 type and M3000 type would dicing blade damage and broken during dressing, because depending on the different wafer material, wafer dicing street, wafer thickness, need apply suitable dicing blade, so dressing board must use for all type dicing blade, M5000 type not occur any abnormal and damage during dressing, and suitable for all type dicing blade, so final we select M5000 type dressing board to evaluate.

TABLE V: DRESSING BOARD EXPERIMENT RESULT

\begin{tabular}{|c|ccc|}
\hline BOARD TYPE & M5000 & M4000 & M3000 \\
\hline A BLADE & Excellent & Damage & Damage \\
\hline B BLADE & Excellent & Acceptable & Damage \\
\hline
\end{tabular}

The optimal dressing parameters were the blade rotation of 40,000 rpm and blade dressing cutting depths is $250 \mathrm{um}$ and $50 \mathrm{um}$, with different dressing speeds.

\section{B. Improvement Effect Confirm}

According the optimal experiment parameter result, next step we use the real product to re-confirm the dressing effect, take the abnormal blade which surface cover and remain the film glue to dressing by the optimal dressing board and parameter, after experiment found wafer dicing blade surface glue can be remove, so this method is effective to improvement this issue, and can apply to the mass production show in Fig. 9.
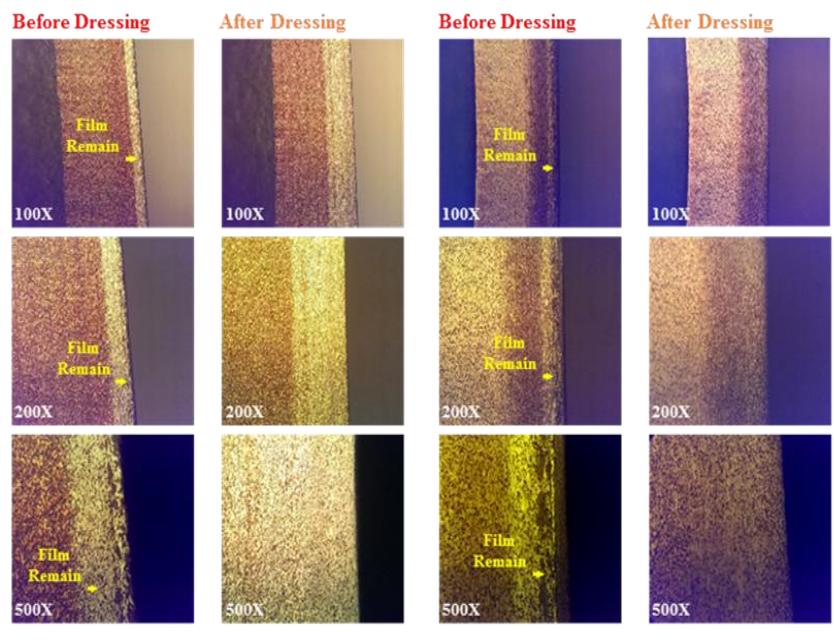

Fig. 9. Dressing result re-confirm photo.

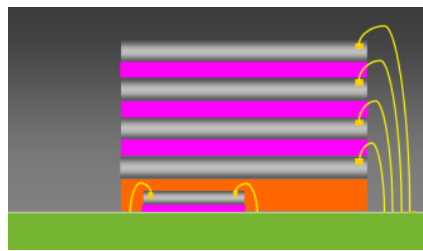

Fig. 10. FOD package.

\section{CONCLUSION}

In this paper, we have improved wafer saw FOW film burr issues, resulting in significant contributions to obtain enhanced yield and cost reductions. However, there are other challenges for the future in addition to the current approach for cutting using lasers. In the IC package technology is a difficult challenge higher, thinner grain thickness, more layers of the stack and other grains.

Another recent technology to resolve film on die (FOD) is to use film material coated grains, where the film consists of thicker material (150 um), as shown in Fig. 10. This causes a higher bound on wafer cutting, which is a difficult problem that we need to solve. This is our next goal, and laser cutting methods are the next-generation product technology trends [6], [7].

\section{REFERENCES}

[1] C. H. Toh, M. Gaurav, T. H. Hong, and P. L. O. Wilson, "Die attach adhesives for 3D same-sized dies stacked packages," in Proc. the IEEE 58th Electronic Components and Technology Conference, pp.1538-1543, May 2008.

[2] M. Teo, S. C. Kheng, and C. Lee, "Process and material characterization of Die Attach Film (DAF) for thin die applications," in Proc. the IEEE Electronic Materials and Packaging International Conference, pp.1-4, Dec. 2010.

[3] C. L. Chung, C. W. Ku, H. C. Hsu, and S. L. Fu, "Comparison between Die Attach Film (DAF) and Film over Wire (FOW) on Stack-die CSP Application," in Proc. the IEEE Microelectronics and Packaging Conference, pp.1-3, Jun. 2009. 
[4] K. W. Shi, K. Y. Yow, and R. Khoo, "Developments of blade dressing technique using $\mathrm{SiC}$ board for $\mathrm{C} 90$ low-K wafer sawing," in Proc. the IEEE 13th Electronics Packaging Technology Conference, pp.122-128, Dec. 2011.

[5] K. W. Shi, K. Y. Yow, and R. Khoo, "Investigations of the effects of blade type, dicing tape, blade preparation and process parameters on $55 \mathrm{~nm}$ Node Low-K Wafer," in Proc. the IEEE 34th Electronic Manufacturing Technology Symposium, pp.1-6, Dec. 2010.

[6] M. Kumagai, N. Uchiyama, E. Ohmura, R. Sugiura, K. Atsumi, and K. Fukumitsu, "Advanced dicing technology for semiconductor wafer-Stealth dicing," in Proc. IEEE Transactions on Semiconductor Manufacturing, pp. 259 - 265, Aug. 2007.

[7] K. F. Lim, "Alternative dicing die attach film method for high volume small dice application," in Proc. the IEEE 34th Electronic Manufacturing Technology Symposium IEMT, pp. 1-6, Dec. 2010.

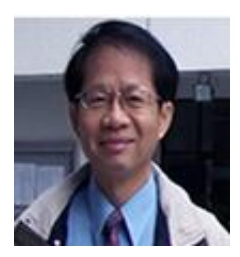

Te-Jen Su received the Ph.D. degree in electrical engineering from National Cheng-Kung University Tainan Taiwan, in 1989. He is currently a professor with the Department of Electronic Engineering, National Kaohsiung University of Applied Sciences, Kaohsiung, Taiwan. His research interests include intelligent control systems, embedded processor design and satellite communication system.

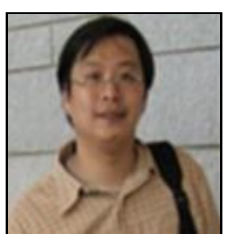

Chien-Liang Chiu received the Ph.D. from the Department of Photonics, National Sun Yat-sen University, Kaohsiung, Taiwan, in 2009. He is currently an Assistant Professor with the Department of Electronic Engineering, National Kaohsiung University of Applied Sciences, Kaohsiung, Taiwan. His research interests include Optoelectronic,
Integrated Design, Measurement Devices, Optical Materials, Analysis, Photolithography, Process Etching, Waveguide Simulation .

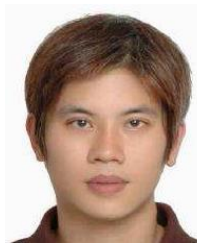

Yi-Feng Chen received the Ph.D. student from the Department of Electronic Engineering, National Kaohsiung University of Applied Sciences, Kaohsiung, Taiwan, in 2015, and the M.S. degree from the Department of Electronic Engineering, National Kaohsiung University of Applied Sciences, Kaohsiung, Taiwan, in 2015. His research interests include IC assembly process and Semiconductor

materials.

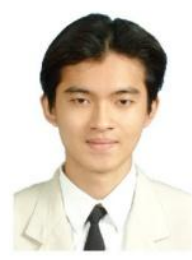

Tung-Yeh Tsou received the M.S. degree from the Department of Electronic Engineering, National Kaohsiung University of Applied Sciences, Kaohsiung, Taiwan, in 2012. He currently serves on the Chunghwa Telecom Company, engaged in the planning and design work. His research interests include communication theory and application, ASP. NET programming language development and cloud computing database

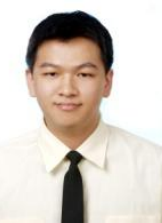

Shih-Mine Wang received the Ph.D. student from the Department of Electronic Engineering, National Kaohsiung University of Applied Sciences, Kaohsiung, Taiwan, in 2015, and the M.S. degree from the Department of Information Management, National Kaohsiung First University of Science and Technology, Kaohsiung, Taiwan, in2007. His research interests include human factor engineering, system analysis and design, computer networks and internets, enterprise resource planning. 